\title{
Enhancing the e-commerce application in SMEs
}

\author{
Van Dung $\mathrm{Ha}^{\mathrm{a}^{*}}$

\begin{tabular}{l}
\hline C H R O N I C L E \\
\hline Article history: \\
Received: January 19, 2020 \\
Received in revised format: \\
March 25 2020 \\
Accepted: April 20, 2020 \\
Available online: \\
April 20, 2020 \\
\hline Keywords: \\
E-commerce \\
Readiness \\
Awareness \\
Barriers \\
Support
\end{tabular}

${ }^{a}$ Banking University Ho Chi Minh City, Vietnam

\section{A B S T R A C T}

\begin{abstract}
E-commerce can optimize the communications between producers, distributors, consumers, and even policy makers. However, due to many reasons, the application of e-commerce by small and medium-sized enterprises (SMEs) in developing economies is still limited. This study focuses on determining the determinants of the application of E-commerce model in SMEs in Ho Chi Minh City. Then, some policy implications are proposed to promote e-commerce model in SMEs in Ho Chi Minh City. Based on the survey of 302 SMEs in Ho Chi Minh City, the paper has employed statistical methods, assessing the reliability by Cronbach's Alpha scale, Exploratory Factor Analysis (EFA), correlation analysis as well as linear regression model (OLS) for analysis. The results show that the enterprise's readiness, awareness of benefits of e-commerce and supporting policies positively affect the application of E-commerce. E-commerce adoption barriers negatively affect Ecommerce applications of SMEs in Ho Chi Minh City.
\end{abstract}

\section{Introduction}

Entering the world economic integration environment, the biggest turning point is the application of electronics, telecommunications and Internet in the process of production and business operation. The development of electronic commerce (Ecommerce) in recent years has proved its important role in many research areas like economics, management, technology, marketing, or finance (Hashim \& Noor, 2014). E-commerce can generate benefits for not only developed countries but also developing economies (Biagi \& Falk, 2017; Lee et al., 2019). The development and application of E-commerce, however, is now facing many obstacles which come from economic environment like infrastructure, finance, capital to legal structure such as lack of regulations, out of date laws, etc. (Kurnia et al., 2015). So, the utilization of E-commerce benefits is still low in developing economies (Kshetri, 2008). In firm level, attracting, maintaining and raising the number of customers is crucial for their survival. E-commerce is considered as one method to do this via marketing, selling, integrating, and increasing customers (Choshin \& Ghaffari, 2017). More specifically, it is the application of E-commerce that is considered a reasonable and pioneering step for the process of improving the competitiveness and promoting the growth of organizations (Susanty et al., 2020). In addition, E-commerce can help firms generate valuable benefits, which could save time and costs, improving competitiveness, and gaining high profits (Biagi \& Falk, 2017; Saridakis et al., 2018, Qi et al., 2020). In the current conditions of economic development and integration, big cities such as Ho Chi Minh City, Hanoi City, and Danang City are evaluated as the fastest gateway to the advanced achievements in science and technology of the world and E-commerce has become one of the most effective ways for firms in these cities to get success. Until now, the literature relating to determinants of applications of E-commerce in firms is still rare, especially for SMEs in Ho Chi Minh City. Therefore, this research can contribute to the literature by filling this research gap. The study will empirically identify and measure the impacts of different factors on the application of E-commerce in SMEs in Ho Chi Minh City. Then, the paper proposes some policy implications to increase the application of E-commerce in SMEs in this area. 
The rest of the paper is organized as follows. The second part will introduce the literature review as well as propose some research hypotheses. The third part will present the research methodology while empirical results will be discussed in forth section. The last section will conclude the study as well as give out some policy implications.

\section{Literature review and hypotheses}

Today, the benefits of commerce have been enlarged by the development of information technology as well as communications. In line with the expansion of information technology, firms become more familiar with digital and online business in order to develop market structure, to reduce costs of operation, or to connect customers more efficiently. The positive impacts of information technology can even get through both customers and services (Waseem et al., 2019). E-commerce can help SMEs in both market penetration and financial benefits. SMEs are normally difficult to access to many large markets, which require some entrance requirements such as capital, product diversity, brand, or shares. Utilizing information technology, SMEs can easier access to these markets. Online and digital business can also reduce operation costs of SMEs (Fatta et al., 2018; Waseem et al., 2019). According to Susanty et al. (2020), E-commerce includes the production, advertising, sales and distribution of products that are purchased and sold on the Internet, but delivered tangibly. Both product delivery and information are digitized via the Internet. In another study, Dahbi and Benmoussa (2019) employ qualitative method to explore the determinants of SMEs adoption of E-commerce in Morocco. Four groups of SMEs including travel agencies, cosmetic companies, artisanal candle companies and textile companies have been examined. The degree of E-commerce adoption among Moroccan SMEs could be hindered by technological, financial, cultural, and organizational categories, in which technological and financial categories are the influenced ones. In Vietnam, the Internet has been around since 1997, which is a milestone of the birth, mature, and development of E-commerce. The development of E-commerce has a profound and comprehensive effect on the socio-economy. After a period of formation and universalization, since 2016, E-commerce has moved to a fast-growing period. According to the Vietnam E-commerce Association's estimates, the growth of E-commerce in 2017 reaches over $25 \%$ and is expected to continue in 2018-2020. However, the determinants of E-commerce application have not fully recognized and the examination of relationships between some factors and E-commerce application can help to partly solve this issue.

\section{Relationship between Enterprise readiness (ER) E-commerce application (AP)}

According to Ling (2001), enterprises with available financial resources, technology, machinery infrastructure and highly qualified human resources will easily apply the E-commerce model to their business operation processes. Along with that, Teo and Tan (1998) pointed out that the possession of good human and financial resources is a prerequisite condition for enterprises to be ready to adopt the E-commerce model to their business operation processes. Enterprises' readiness is much depended on resource availability of these enterprises such as technological and financial resources (Rana et al., 2019). In SMEs, resources become more important to sustain their business, and enterprises' readiness positively influences E-commerce applications (Lim et al., 2018). In this study, enterprises' readiness is considered one of the organizational determinants that influence E-commerce applications by the SMEs. In enterprises' readiness, the extent of technological infrastructure, technical skills in business, and relevant systems which can promote E-commerce application is investigated. So, enterprises' readiness positively influences E-commerce applications by the SMEs (Rahayu \& Day, 2015). Therefore, this study proposes the first hypothesis.

\section{$\mathbf{H}_{1}$ : Enterprises' readiness positively impacts on E-commerce applications of enterprises.}

\section{Relationship between Awareness of E-commerce benefits (BE) E-commerce application (AP)}

The benefits from E-commerce are also considered as one of the prerequisites for enterprises to apply the E-commerce model to their business. Moreover, the more enterprises realize the benefits that E-commerce brings, the easier it will be for them to accept E-commerce model during their operation. According to Susanty et al. (2020), awareness of E-commerce benefits of E-commerce is that enterprises will find themselves saved in terms of cost, time and human resources for the production and business process. Rahayu and Day (2015) refer to the technological context those aspects such as awareness of E-commerce benefits, compatibility, and cost, that influence the adoption of E-commerce technology; the awareness of E-commerce benefits refers to the degree of acceptance of the possible advantages that E-commerce technology can provide for the organization. So awareness of E-commerce benefits positively influence E-commerce applications by the SMEs. Therefore, perceived benefits are factors that need to be considered when analyzing E-commerce applications for SMEs (Kabango \& Asa, 2015; Rana et al., 2019). Therefore, this study proposes the second hypothesis is as follows,

\section{H2: Awareness of E-commerce benefits of E-commerce positively impacts on E-commerce applications of enterprises.}

\section{Relationship between E-commerce application barriers (BA) E-commerce application (AP)}

However, according to Ling (2001), the application of E-commerce model also has some certain barriers, which is a longstanding habit in the production and business process that somewhat limits the application of E-commerce model of enterprise 
owners. In addition, the limitation of human resources, financial, organizational, cultural constraints and the lack of awareness of the benefits that E-commerce model carry out have created barriers for enterprises in applying the E-commerce model (Teo \& Tan, 1998; Dahbi \& Benmoussa, 2019). And Rahayu and Day (2015) have proved that owners' IT capacities, experience, and modernity can E-commerce application by SMEs in developing economies, so E-commerce application barriers influences E-commerce applications by the SME. Barriers of E-commerce application is examined and considered independent variables in both diffusion and adoption equations. Negative perception of technological implementation, which discourages the application of E-commerce, is main theme of the barrier. Because of high cost, the application process becomes more difficult and sophisticated whenever technology implementation is still complex and the perceived obstacle exists (Lim et al., 2018). Therefore, this study proposes the third hypothesis as follows,

\section{H3: E-commerce application barriers negatively impact on E-commerce applications of enterprises.}

\section{Relationship between Support policies (PO) E-commerce application (AP)}

And finally, the supporting policies (that can be tax incentives, perfecting the legal framework on E-commerce, consulting activities, supporting enterprises in learning E-commerce) for enterprises to apply E-commerce model is a condition that promotes enterprises to be ready to apply the E-commerce model to their business operation processes in a faster way (Ling, 2001). E-commerce application is also determined by external supports such as supports form government and IT vendors (Rahayu \& Day, 2015; Dahbi \& Benmoussa, 2019). Kabango \& Asa (2015) indicate that in every developing economy the government plays an important role in facilitating the essential requirements for the development of e-commerce. In order to provide robust and secure online payment options, to ensure a stable information technology infrastructure, to provide sufficient programs, and to build up awareness of using different means of media and education institutions are main duties of the government (Kabango \& Asa, 2015). SMEs as commonly known face scare resources in human, financial, and information technology resources. Government's supports via its policies and regulations are priceless for SMEs engaging to E-commerce or online business transactions (Rahayu \& Day, 2015). So, Rahayu and Day (2015) have proved that the supporting policies positively influence E-commerce applications of the SMEs. Therefore, this study proposes the fourth hypothesis is as follows,

\section{$\mathbf{H}_{4}$ : The supporting policies have a positive impact on E-commerce applications of enterprises.}

\section{Research Methodology}

In this study, both qualitative and quantitative methods are used to investigate the determinants of E-commerce application of SMEs in Ho Chi Minh City.

Table 1

Measurement scales for the factors

\begin{tabular}{|c|c|c|c|c|}
\hline No. & Factor & Symbol & Measurement content & Author \\
\hline 1 & \multirow{4}{*}{ Enterprise readiness } & ER1 & Enterprises have sufficient financial resources to apply E-commerce & \multirow{4}{*}{$\begin{array}{c}\text { Teo and Tan } \\
(1998), \text { Ling } \\
(2001)\end{array}$} \\
\hline 2 & & ER2 & $\begin{array}{l}\text { Enterprises have sufficient information technology resources to conduct E- } \\
\text { commerce }\end{array}$ & \\
\hline 3 & & ER3 & $\begin{array}{l}\text { Enterprises have human resources with information technology qualifica- } \\
\text { tions meeting the implementation of E-commerce }\end{array}$ & \\
\hline 4 & & ER4 & $\begin{array}{l}\text { Enterprises have infrastructure sources meeting the application of E-com- } \\
\text { merce }\end{array}$ & \\
\hline 5 & \multirow{4}{*}{$\begin{array}{l}\text { Awareness of E-com- } \\
\text { merce benefits }\end{array}$} & BE1 & E-commerce helps enterprises save costs and time & \multirow{4}{*}{$\begin{array}{l}\text { Susanty et al. } \\
\qquad(2020)\end{array}$} \\
\hline 6 & & BE2 & E-commerce helps enterprises approach more customers & \\
\hline 7 & & BE3 & E-commerce helps enterprises access more information & \\
\hline 8 & & BE4 & $\begin{array}{l}\text { E-commerce helps enterprises expand business opportunities, increase sales } \\
\text { and profits }\end{array}$ & \\
\hline 9 & \multirow{5}{*}{$\begin{array}{l}\text { E-commerce applica- } \\
\text { tion barriers }\end{array}$} & BA1 & $\begin{array}{l}\text { Traditional purchase and sale practices hinders the application of E-com- } \\
\text { merce }\end{array}$ & \multirow{5}{*}{$\begin{array}{c}\text { Teo and Tan } \\
(1998), \text { Ling } \\
(2001)\end{array}$} \\
\hline 10 & & BA2 & Human resources have not met the demand of applying E-commerce & \\
\hline 11 & & BA3 & Investment costs for E-commerce are limited & \\
\hline 12 & & BA4 & Awareness of benefits of E-commerce is not clear & \\
\hline 13 & & BA5 & E-commerce is not consistent with the way enterprises do business & \\
\hline 14 & \multirow{4}{*}{ Support policies } & PO1 & The government provides tax incentives & \multirow{4}{*}{$\begin{array}{c}\text { Teo and Tan } \\
(1998), \text { Ling } \\
(2001)\end{array}$} \\
\hline 15 & & $\mathrm{PO} 2$ & The government provides infrastructures at a reasonable cost & \\
\hline 16 & & PO3 & The legal environment for E-commerce has been complete & \\
\hline 17 & & PO4 & $\begin{array}{l}\text { The market has consultancy, design and development of electronic infor- } \\
\text { mation }\end{array}$ & \\
\hline 18 & \multirow{3}{*}{$\begin{array}{l}\text { E-commerce applica- } \\
\text { tion }\end{array}$} & AP1 & $\begin{array}{l}\text { Enterprises have sufficient human and material resources to apply E-com- } \\
\text { merce }\end{array}$ & \multirow{3}{*}{$\begin{array}{c}\text { Teo and Tan } \\
(1998), \text { Ling } \\
(2001)\end{array}$} \\
\hline 19 & & AP2 & E-commerce really benefits enterprises & \\
\hline 20 & & AP3 & Enterprises get the support they need to apply E-commerce & \\
\hline
\end{tabular}


- Qualitative method: the preliminary research hypotheses and models are conducted basing on the literature review and overview of the previous studies. Then, a group discussion with 7 experts who are working in E-commerce business to adjust the observed variables of the factors: ER (Enterprise readiness), BE (Awareness of E-commerce benefits), BA (E-commerce application barriers), PO (Support policies) and AP (E-commerce application) in the preliminary research model. The results of this stage will form the measurement scale and questionnaire for collecting the data in quantitative research.

- Quantitative method: The convenient sampling method is used for collecting data. The sample size is of 302 SMEs in Ho Chi Minh City. The questionnaire is sent directly via email to SMEs in the prepared lists. SPSS 20 software is used to process the data. Statistics, Assessments of the reliability of the scales by Cronbach's Alpha test, Exploratory factor analysis (EFA) by Bartlett and KMO tests, and Linear Equation Model (OLS) are main quantitative solutions to analyze the enhancing of Ecommerce model in SMEs in Ho Chi Minh City.

According to Hoang and Chu (2008), the minimum sample size is $\mathrm{n}=5 \times \mathrm{x}$ (x: number of variables/measurement scale). In this study, 20 observed variables are used, so the minimum sample size will be $5 \times 20=100$ observations. The paper conducts a survey with 320 questionnaires, of which the number of valid questionnaires was 302 to ensure the reliability and quality of the results.

Table 2

Descriptive statistics

\begin{tabular}{cccc}
\hline Variable & Content & Frequency (n) & Percent (\%) \\
\hline \multirow{2}{*}{ Gender } & Male & 198 & 65.6 \\
& Female & 104 & 34.4 \\
\hline \multirow{2}{*}{ Educational level } & Intermediate, college & 36 & 11.9 \\
& Undergraduate & 181 & 59.9 \\
\hline \multirow{2}{*}{ Age } & Graduate & 85 & 28.1 \\
& Under 30 years old & 46 & 15.2 \\
& From 30 to 40 years old & 153 & 50.7 \\
\hline \multirow{2}{*}{ Working position } & From 41 to 50 years old & 98 & 32.5 \\
& Over 50 years old & 5 & 1.7 \\
\hline & Head/Deputy Head of Department & 44 & 14.6 \\
\hline & Deputy Director & 176 & 58.3 \\
\end{tabular}

Among 302 surveyed subjects, whose positions are head/deputy head or higher, $27.2 \%$ are directors; $58.3 \%$ are deputy directors. $83.2 \%$ of manager's age are from $30-50$; the educational level of respondents is mainly undergraduate, accounting for $59.9 \%$ and male accounts for $65.6 \%$ while female respondents account for $34.4 \%$.

\section{Empirical Results}

The reliability test results of scale indicate that, the Cronbach's Alpha coefficient gets the maximum value of 0.929 , which belongs to the factor Supporting policies while the lowest Cronbach's Alpha coefficient is 0.830, which belongs to the Ecommerce application factor. The Cronbach's Alpha coefficients of E-commerce application barriers, Enterprise readiness, and Awareness of E-commerce benefits are 0.914, 0.904, and 0.888, respectively. It is shown that all Cronbach's Alpha coefficients of the factors are from 0.8 or more. And all variables included in Cronbach's alpha analysis are satisfactory, ie the total correlation coefficient is greater than 0.3 . Therefore, all variables (20, including 17 independent variables and 3 dependent variables) are guaranteed in the EFA factor analysis.

Table 3

Cronbach's Alpha analysis results

\begin{tabular}{lcc}
\hline Factor & Cronbach's alpha & Variable \\
\hline Enterprise readiness & 0.906 & 4 \\
Awareness of E-commerce benefits & 0.888 & 4 \\
E-commerce application barriers & 0.914 & 5 \\
Support policies & 0.929 & 4 \\
E-commerce application & 0.830 & 3 \\
\hline
\end{tabular}

All 17 variables of independent factors satisfying Cronbach's Alpha reliability analysis criteria were included in the exploratory factor analysis (EFA). The results of EFA analysis are shown that the KMO coefficient equals to 0.627 , which is greater than 0.5 so that it is satisfactory. The significant level of the Sig. taken from Bartlett's test equals to 0.000, which is less than $5 \%$ so that it is satisfactory. The Total Variance Explained equals to $79.837 \%$, which is greater $50 \%$ so that it is satisfactory. 
The number of extracted factors is 4 , so it is consistent with the hypothesis about the components of the measurement scale. At the same time, the eigenvalue equals to 2.525, which is greater than 1 ; the factor loadings are greater than 0.5 and arranged in four groups of separated factors, namely ER (Enterprise readiness), BE (Awareness of E-commerce benefits), BA (Ecommerce application barriers), PO (Support policies), which ensures the inclusion of variables of these factors into the following analysis steps.

Table 4

$\underline{\text { Rotated Component Matrix for independent variables }}$

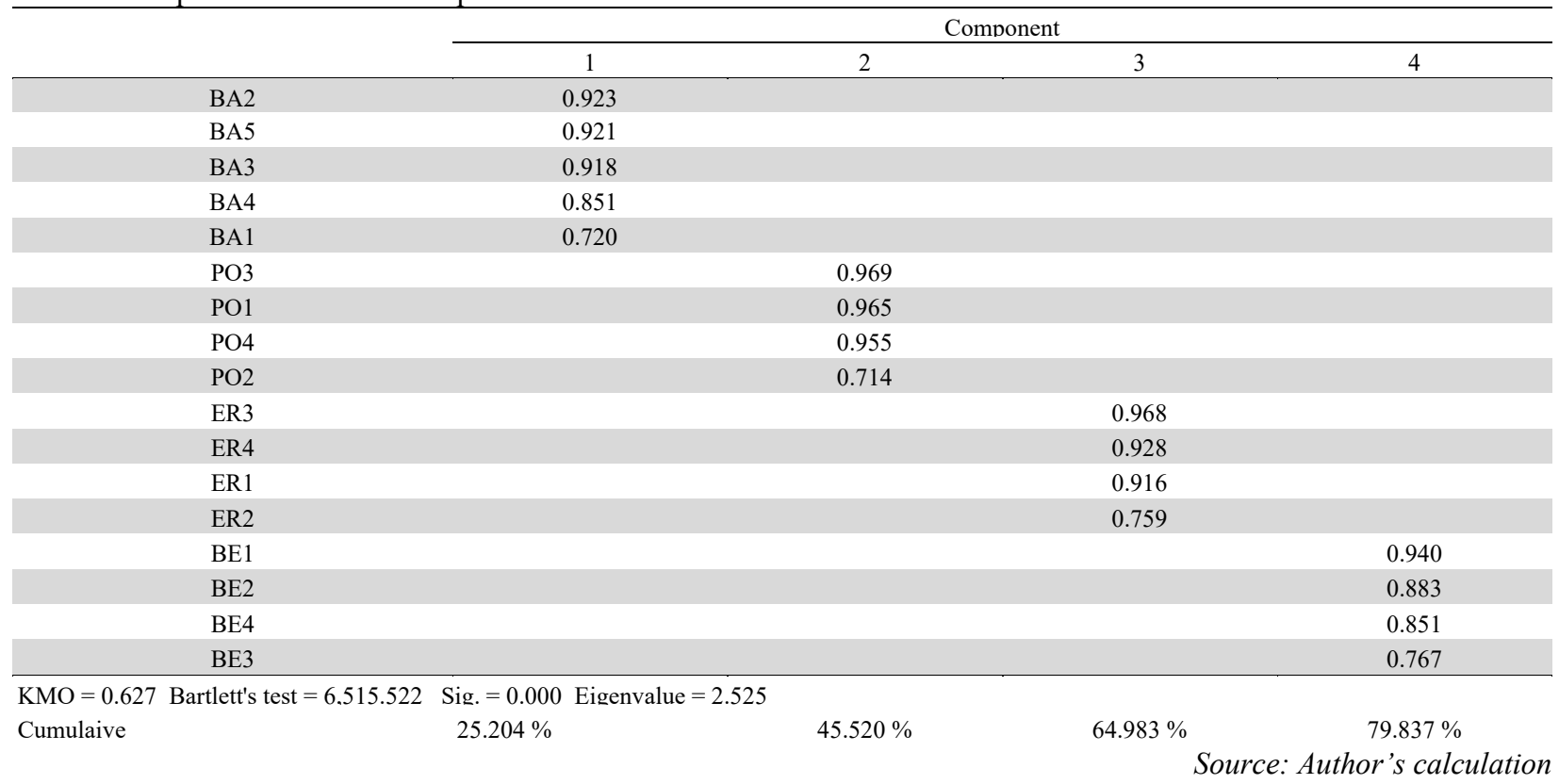

In addition, the EFA factor analysis for E-commerce application factor shows that the KMO value is 0.713 , which is greater than 0.5 so that it is satisfactory. The significant level of the Sig. taken from Bartlett's test equals to 0.000, which is less than $5 \%$ so that it is satisfactory. The Total Variance Explained equals to $74.724 \%$, which is greater $50 \%$ so that it is satisfactory. The number of extracted factors is 1 , the eigenvalue equals to 2.242 , which is greater than 1 ; the factor loadings are greater than 0.5 , and arranged in one groups of separated factors, namely AP (E-commerce application), which ensures the inclusion of variables of these factors into the following analysis steps.

Table 5

Factor load factor for dependent variables

\begin{tabular}{cccc}
\hline & Component & \\
\hline AP2 & 0.885 & Bartlett's test & Somponent \\
AP3 & 0.872 & 347.131 & 0.000 \\
AP1 & 0.835 & Eigenvalue & Cumulative \\
KMO & 0.713 & 74.724 & Source. Author's calculation
\end{tabular}

The correlation analysis of factors (Table 6) indicate the E-commerce application dependent factor has a positive/same direction correlation with the ER (Enterprise readiness), BE (Awareness of E-commerce benefits), PO (Support policies) and negative/opposite direction correlation with BA (E-commerce application barriers). And the Sig. coefficients of the factors are smaller than 5\% (i.e. less than 0.05 ). This result ensures the correlation between the factors and it is suitable to run the linear regression model.

Table 6

Correlation analysis results

\begin{tabular}{ccccccc}
\hline & Enterprise readiness & $\begin{array}{c}\text { Awareness of E-com- } \\
\text { merce benefits }\end{array}$ & $\begin{array}{c}\text { E-commerce } \\
\text { application barriers }\end{array}$ & $\begin{array}{c}\text { Support } \\
\text { policies }\end{array}$ & $\begin{array}{c}\text { E-commerce } \\
\text { application }\end{array}$ \\
\hline \multirow{2}{*}{$\begin{array}{c}\text { E-commerce } \\
\text { application }\end{array}$} & Pearson Correlation & $0.353^{* * *}$ & $0.569^{* *}$ & $-0.237^{* *}$ & $0.200^{* *}$ & \\
& Sig. (2-tailed) & 0.000 & 0.000 & 0.000 & 0.000 & 1 \\
& $\mathrm{~N}$ & 302 & 302 & 302 & 302 & 302 \\
\hline
\end{tabular}

$* * .<0.01$ (signification at $1 \%$ ),.$<0.05$ (signification at $5 \%$ ).

Source: Author's calculation

The results of the regression model analysis show that the factors ER (Enterprise readiness), BE (Awareness of E-commerce benefits), PO (Support policies) positively affect AP (E-commerce application); and BA (E-commerce application barriers) 
negatively affect the AP (E-commerce application). The $\mathrm{R}^{2}$ index is 0.586 , this result shows that the model fits $58.6 \%$, or in other words $58.6 \%$ of the variation of E-commerce application factor is explained by 4 factors: ER (Enterprise readiness), BE (Awareness of E-commerce benefits), BA (E-commerce application barriers), PO (Support policies). Using the F test in ANOVA variance analysis shows that the $F$ value is 70.183 with the significance Sig. is 0.000 less than 0.05 , it shows that the combination of 4 independent factors in the model can explain the change of E-commerce applications.

Table 7

$\underline{\text { Regression model results }}$

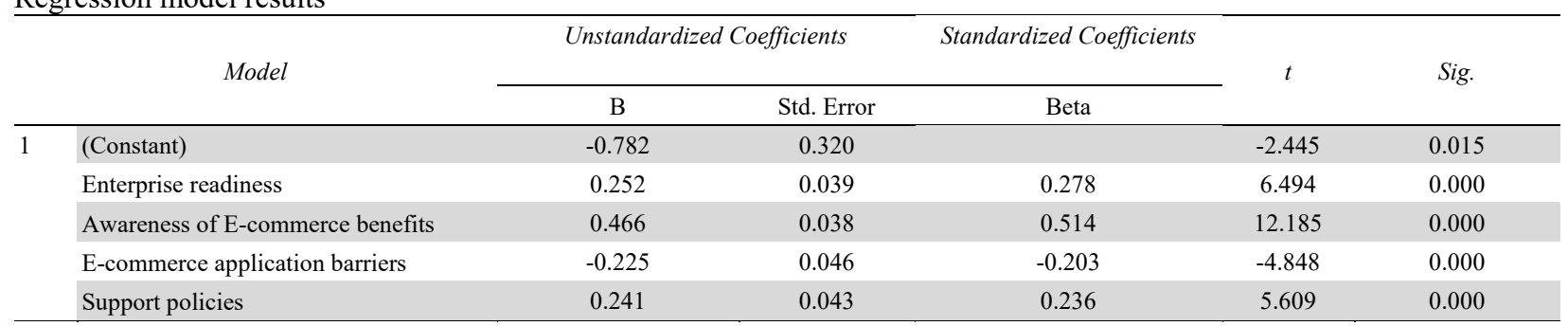

$\mathrm{R}^{2}=0.586 ; \mathrm{F}=70.183$; Sig. $=0.000$

a. Dependent Variable: E-commerce application

Source: Author's calculation

The model (the unstandardized regression coefficient) that shows the relationship of factors is:

$$
A P=-0.782+0.252 \times E R+0.466 \times B E-0.225 \times B A+0.241 \times P O+e_{i}
$$

The standardized regression coefficients indicate that the largest level of influence on AP (E-commerce application) is the factor BE (Awareness of E-commerce benefits) (BE has Beta $=0.514$, positive effect), when the BE (Awareness of E-commerce benefits) is better (increase by 1 unit), AP (E-commerce application) increases by 0.389 unit. Next, ER (Enterprise readiness) positively affects AP (E-commerce application) (ER has Beta $=0.278$, positive effect), when the ER (Enterprise readiness) is better (increase by 1 unit), AP (E-commerce application) increases by 0.278 unit. PO (Support policies) positively affects AP (E-commerce application) (PO has Beta $=0.236$, positive effect), when the PO (Support policies) is better (increase by 1 unit), AP (E-commerce application) increases by 0.236 unit. And finally, BA (Ecommerce application barriers) negative effect AP (E-commerce application) (BA has Beta $=0.203$, negative effect), when the BA (Ecommerce application barriers) is better (increase by 1 unit), AP (E-commerce application) reduction by 0.203 unit.

Table 8

Regression model results

\begin{tabular}{|c|c|c|c|}
\hline \multirow{2}{*}{ No. } & \multirow{2}{*}{ Factors } & \multicolumn{2}{|c|}{ Collinearity Statistics } \\
\hline & & Tolerance & VIF \\
\hline 1 & Enterprise readiness & 0.945 & 1.059 \\
\hline 2 & Awareness of E-commerce benefits & 0.972 & 1.029 \\
\hline 3 & E-commerce application barriers & 0.987 & 1.013 \\
\hline 4 & Support policies & 0.980 & 1.020 \\
\hline
\end{tabular}

Along with that, the results show that the coefficient VIF of ER (Enterprise readiness), BE (Awareness of E-commerce benefits), BA (E-commerce application barriers), PO (Support policies) are 1.059; 1.029; 1.013; 1.020 are within the allowed level (less than 5), showing that there is no multicolinearity in the model.

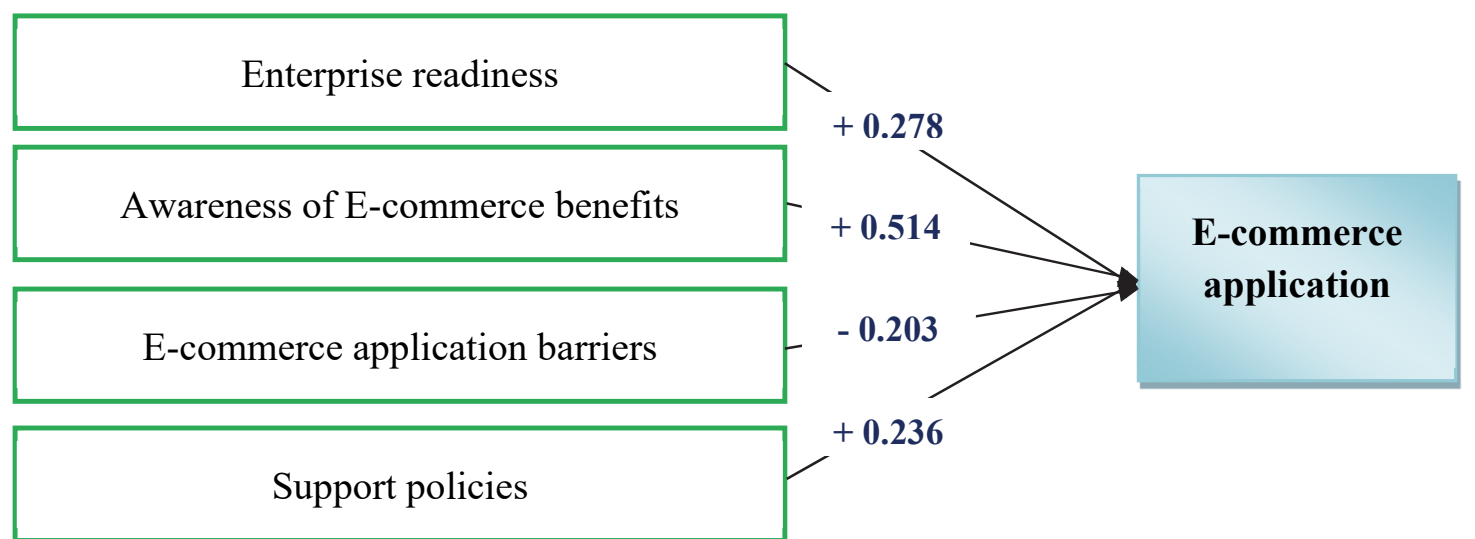

Fig. 1. Research model results 


\section{Conclusions and Policy implications}

The application of E-commerce in SMEs is extremely important to maintain and foster the number of firm customers. This study aims at finding determinants of E-commerce application in SMEs in Ho Chi Minh City. This study has employed qualitative method via group discussion among E-commerce experts to re-modify the factors as well as the questionnaire. Then, quantitative method is used to classified questions and data via Cronbach's Alpha test, exploratory factor analysis (EFA) with Bartlett and KMO tests, and Linear Equation Model (OLS). Basing on the sample of 302 respondents from SMEs, the study finds that awareness of E-commerce benefits, readiness of enterprises, support policies, and E-commerce application barriers are determinants of E-commerce application of SMEs in Ho Chi Minh City. While E-commerce application barriers such as traditional purchase and sale practices, insufficient human resources, investment costs, insufficient awareness of Ecommerce business, and inconsistent business strategy hinder the application of E-commerce, other determinants have positive impacts on E-commerce application. In order to increase the E-commerce application of SMEs in Ho Chi Minh City, comprehensive solutions should be simultaneously done and thus it gives out some policy implications. Firstly, firms need to be ready for the E-commerce application. Firm readiness ranges from financial resources, technology resources, infrastructure resources, and human resources. Employers and employees have to take part in training courses of departments and agencies on E-commerce programs to capture essential skills of E-commerce. It is important to increase training of human resources to minimize the barrier of the shortage of human resources that does not meet the needs of applying E-commerce model in business activities. The knowledge must be updated while deficiency in E-commerce technology could hinder the development of firms. Firms with managers who have adequate knowledge would operate more efficiently in E-commerce (Rana et al., 2019). Besides the quality of human resources, the quantity of labor should be fulfilled. In accordance to human resources, other factors have to be sufficient. Finance has to be enough for investing, maintaining, and covering costs; Information technology or current technology within the business must be compliment E-commerce sufficiently. Other infrastructure as building, store house, transportation, and delivery services have to be well-organized and developed. Secondly, awareness of E-commerce benefits should be focused. The managers should be in the first line of changing towards E-commerce application since most employees are those who do not want to change. Especially in SMES which have relatively small number of labor force, the managers are easier to apply E-commerce model due to its small scale. Training courses of E-commerce for employees who must aware the benefits as well as the costs of E-commerce are necessary. Furthermore, firms should have a team specialized in E-commerce activities, grasping and proposing plans to apply E-commerce to their business activities.

Thirdly, policy support mostly comes from the central and local authorities. However, firms need to boldly propose the necessary needs so that government, agencies as well as cities have appropriate support policies for the development of E-commerce in the area. E-commerce operates in IT infrastructure so it requires firms invest much capital, which is often insufficient in SMEs. Tax incentives should be given for SMEs that start E-commerce application. The reduction or tax-free first 3 to 5 years may motivate SMEs to engage to E-commerce. Other supports from government could be infrastructure of E-commerce such as internet, customs, and audit, which have to supply to push the E-commerce ahead. In developing economies, investment on these infrastructures often come from the government or from state-owned enterprises since private firms are relatively small and weak in capital accumulation. So, the government policies will decide the level of infrastructure development or in other words, these issues are totally in hands of the government. In addition, the legislation on E-commerce should be complete and stable. To do so, it needs to reference to law system in developed economies since in Vietnam, like other developing economies, business law changes quite oft. Unstable policies will increase firm operating costs and thus demotivate the E-commerce application of SMEs. Last but not least, traditional purchase and sale practices and inconsistent business strategy may hinder the E-commerce application. SMEs are often familiar to traditional sale practices rather than E-commerce model and it takes time for firms to get absorb new sale practices. How fast the procedure is completely depends on the will and needs of the managers. Another barrier that hinders the application of E-commerce and should be removed is the inconsistent business strategy. E-commerce is a strategic and unavoidable trend, and only SMEs who have stably positive policies toward E-commerce can get benefits from E-commerce. So, a stable business strategy toward E-commerce is needed. The research still has certain limitations. The study is limited by its sample size of only 302 and is only done for SMEs in Ho Chi Minh City. The future research could extend the sample size or extend the scope to all types of firms rather than only SMEs in Ho Chi Minh City. Along with that, the research has not gone into analyzing the application of E-commerce in specific industries. If the study could conduct across multiple industries with varying level of E-commerce and technological development, the results would be more intensive and interesting. Moreover, the researchers could utilize more factors which are suitable to their context and samples, and empirically test their hypotheses and performance.

\section{References}

Biagi, F., \& Falk, M. (2017). The Impact of ICT and E-Commerce on Employment in Europe. Journal of Policy Modeling, 39(1), 1-18. http://dx.doi.org/10.1016/j.jpolmod.2016.12.004

Choshin, M., \& Ghaffari, A. (2017). An investigation of the impact of effective factors on the success of e-commerce in smalland medium-sized companies. Computer on Human Behavior, 66, 67-74. http://dx.doi.org/10.1016/j.chb.2016.09.026

Dahbi, S., \& Benmoussa, C. (2019). What Hinder SMEs from Adopting E-commerce? A Multiple Case Analysis. Procedia Computer Science, 158, 811-818. 
Fatta, D. D., Patton, D, \& Viglia, G. (2018). The determinants of conversion rates in SME e-commerce websites. Journal of Retailing and Consumer Services, 41, 161-168. https://doi.org/10.1016/j.jretconser.2017.12.008

Hashim, N. A., \& Noor, S. M. (2014). An Investigation of Key Adoption of E-Commerce in SMEs in Malaysia. Proceedings of the 26th International Business Research Conference (pp. 1-17). London, UK.

Hoang, T. \& Chu, N. M. N. (2008). Textbook of Data Analysis with SPSS Episodes 1 \& 2. Ho Chi Minh City, Vietnam: Hong Duc Publishing.

Kabango, C. M. \& Asa, A. R. (2015). Factors influencing e-commerce development: Implications for the developing countries. International Journal of Innovation and Economic Development, 1(1), $64-72$.

Kshetri, N. (2008). Barriers to e-commerce and competitive business models in developing countries: A case study. Electronic Commerce Research and Applications, 6(4), 443-452.

Kurnia, S., Choudrie, J., Mahbubur, R. M., \& Alzougool, B. (2015). E-commerce technology adoption: A Malaysian grocery SME retail sector study. Journal of Business Research, 68(9), 1906-1918.

Lim, S., \& Trakulmaykee, N. (2018). An empirical study on factors affecting e-commerce adoption among SMEs in west Malaysia. Management Science Letters, 8(5), 381-392.

Ling, C. Y. (2001). Model of factors influences on electronic commerce adoption and diffusion in small \& medium sized enterprises. Paper presented at the Doctoral Consortium of the 9th European Conference on Information Systems. Bled, Slovenia.

Nguyen, D. T. \& Nguyen, T. M. T. (2011). Market research syllabus. Hanoi: Labor Publishing.

Qi, X., Chan, J. H., Hu, J., \& Li, Y. (2020). Motivations for selecting cross-border e-commerce as a foreign market entry mode. Industrial Marketing Management, https://doi.org/10.1016/j.indmarman.2020.01.009.

Rahayu, R., \& Day, J. (2015). Determinant Factors of E-commerce Adoption by SMEs in Developing Country: Evidence from Indonesia. Procedia - Social and Behavioral Sciences, 195, 142 - 150.

Rana, N. P., Barnard, D. J., Baabdullah, A. M. A., Rees, D., \& Roderick, S. (2019). Exploring barriers of m-commerce adoption in SMEs in the UK: Developing a framework using ISM. International Journal of Information Management, 44, 141153. https://doi.org/10.1016/j.ijinfomgt.2018.10.009

Saridakis, G., Lai, Y, Mohammed, A., \& Hansen, J. M. (2018). Industry Characteristics, stages of E-commerce communications, and entrepreneurs and SMEs revenue growth. Technological Forecasting and Social Change, 128, 56-66. http://dx.doi.org/10.1016/j.techfore.2017.10.017

Susanty, A., Handoko, A. \& Puspitasari, N. (2020). Push-pull-mooring framework for e-commerce adoption in small and medium enterprises. Journal of Enterprise Information Management, 33(2), 381-406.

Teo, T. S. H. \& Tan, M., (1998). An empirical study of adopters and nonadopters of the Internet in Singapore. Information \& Management, 34, 339-345.

Waseem, A., Rashid, Y., Warraich, M. A., Sadiq, I. \& Shaukat, Z. (2019). Factors affecting E-commerce potential of any country using multiple regression analysis. Journal of Internet Banking and Commerce, 24(2), 1 - 28.

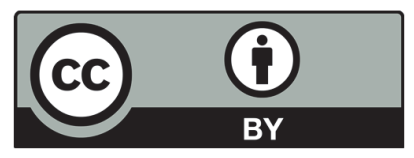

(C) 2020 by the authors; licensee Growing Science, Canada. This is an open access article distributed under the terms and conditions of the Creative Commons Attribution (CC-BY) license (http://creativecommons.org/licenses/by/4.0/). 